\title{
How much do the general public want to be involved in decisions on implementing water fluoridation?
}

\author{
R. J. Lowry, ${ }^{1}$ B. Thompson, ${ }^{2}$ M. A. Lennon, ${ }^{3}$
}

Objective Test general public view about how much they wish to be involved in water fluoridation implementation decisions.

Design Qualitative research using focus group discussions led by an experienced moderator.

Setting Among the general public living in three nonfluoridated areas in England.

Subjects Members of the public more than 20 years of age and by social class.

Results General public wish to be informed of water

fluoridation plans but do not see themselves as being the appropriate implementation arbiters.

Conclusions In the public's eyes, it would be inappropriate and unwelcome to delegate to them the decision about whether to fluoridate the public water supply.

Establishment support for water fluoridation in the United Kingdom remains high: well-respected commentators on public health recommend further implementation to reduce inequalities in dental health, ${ }^{1}$ and the Government recognises this intervention as an important route to improving the health of sections of society. Nevertheless, how to involve the public in the decision-making process when implementing new water fluoridation schemes remains an issue. $^{2}$

Under current legislation, before any new water fluoridation schemes are implemented, the public have to be informed (though not formally consulted), ${ }^{3}$ and in an increasingly consumer-conscious health service, their views are likely to be given even greater importance. Although, according to regular, rigorously-conducted public opinion surveys, public support for water fluoridation remains high, evidence is now emerging on how the public feels about the role they might be ascribed in the implementation of water fluoridation. ${ }^{4}$ More needs to be understood about what the public knows, understands and feels about water fluoridation; the role, if any, they want and feel able to play in decision making about its implementation and the information and other needs they have to discharge this role. Before a greater public involvement in the decision-making process is

${ }^{1}$ Senior Lecturer in Dental Public Health/Consultant in Public Health Medicine, Department of Child Dental Health, Dental School, University of Newcastle upon Tyne NE2 4BW; ${ }^{2}$ Senior Research Consultant, Flat 1a, 89 East Hill, Wandsworth, London SW18 2QD (Formerly: Senior Research Executive, NOP Consumer, Ludgate House, 245 Blackfriars Road, London SE1 9UL); ${ }^{3}$ Professor of Dental Public Health, Department of Clinical Dental Sciences, The University of Liverpool L69 3BX

Correspondence to: $R J$ Lowry

REFEREED PAPER

Received 05.08.99; accepted 04.11.99

(C) British Dental Journal 2000; 188: 500-502 enshrined in public policy, it is important to discover the public's own view of its role. The objective of the study was to test the view of the general public about how much they wish to be involved in water fluoridation implementation decisions.

\section{Methods}

The research adopted a qualitative, focus group methodology. This method is commonly used in market research, and increasingly in medical and dental research. ${ }^{5,6}$ It is particularly suitable for identifying, exploring and explaining complex attitudes and emotions, for example the public's views of priority setting, ${ }^{7}$ and can overcome some of the disadvantages of quantitative methods, especially non-sampling error such as the superficiality of response.

Focus group discussions involve bringing together, in an informal setting, groups of six to eight subjects who are carefully selected in social demographic terms, and asking them to discuss areas of interest under the direction of a group moderator. ${ }^{8}$ The moderator encourages interaction and synergy between group members and ensures that all the issues are explored in depth. Members of the public were recruited to take part in one of six focus groups in three non-fluoridated areas in England according to social class and age (Table 1). Subjects were recruited by trained and experienced market research interviewers according to a strict code of conduct. ${ }^{9}$ Potential recruits who expressed strong views for or against water fluoridation were excluded from the study groups. The groups were not made aware that fluoridation was the core subject for discussion; water fluoridation was but one of a number of issues for discussion about public involvement in matters of local interest (Table 2). Focus group discussions lasting 1.5 hours were held at a central location (for example, a hotel), and subjects were paid a standard fee for participating. The moderator (who conducted and analysed all groups) used a standardised discussion guide and each group was recorded on audio tape for later analysis. High profile media reporting of fluoridation issues was noted if it occurred before any group discussion.

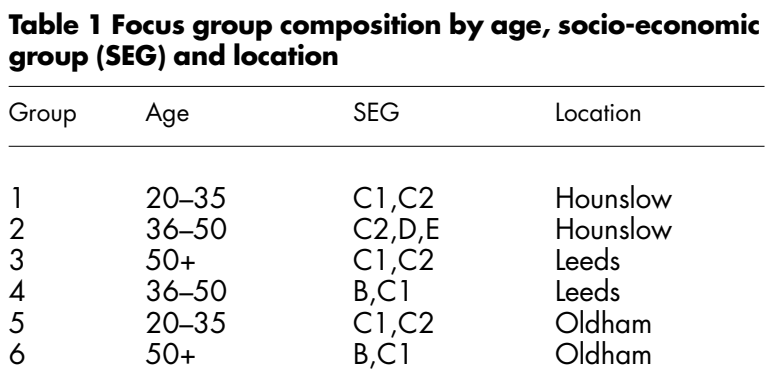




\section{Results}

Awareness of water fluoridation

The topic of water fluoridation was easy to explore in all groups and it did not become the dominant topic of conversation even in groups which took place following an emotive report in a popular television consumer series. Although most group participants were aware of water fluoridation, there were misconceptions: for example, some people mistakenly thought that their water supplies were already fluoridated at the appropriate level. There was little detailed understanding of water fluoridation and confusion surrounding the benefits or possible objections, even in an area where a formal publicity and consultation exercise had been undertaken.

Being involved in decisions

After an initial discussion, the public's involvement in decisionmaking processes was explored in a dynamic fashion. At first, the groups would only talk about the relative importance of services and issues that directly concerned them (for example, local traffic problems) or those that are high profile within the community (such as hospital closures).

To overcome this, a wide range of issues including fluoridation was presented (Table 2), so that they could rank them in relation to their desire to be part of the decision-making process. Groups were divided into sub-groups of two or three people and were given a set of cards on which were written the issues (Table 2), and a board on which the cards could be freely displayed. Each board was marked with a scale with 'definitely would like to be involved with the decision-making process' at one end and 'definitely would not like to be involved with the decision-making process' at the other. The cards were given to the sub-groups and they were asked to place the individual cards along the scale according to their preferred degree of involvement in the decision-making process. Each card was placed independently so that no hierarchy was implied. ${ }^{10}$

This procedure was confusing for participants initially. The very first group started to place all cards on the 'definitely want to be involved' end because they assumed 'being involved' meant 'being informed'. After being told to assume that they would have all the information they desired and just to concentrate on the involvement in decision-making, they (and all subsequent sub-groups) were able to place the cards along the scale of involvement to reflect their intended views. Water fluoridation was consistently among the issues which members of the group placed as warranting a low level of involvement (Table 3 ).

\section{The mechanics of 'consultation'}

The groups showed a general lack of knowledge about public 'consultation' on local issues: feelings of lack of trust, communication,

Table 2 Local issues for discussion in focus groups

- Water fluoridation

- Food fortification

- Closure of local hospital

- Closure of casualty facility

- Relocation of well baby clinic

- Relocation of dental clinic

- Relocation of schools

- Area redevelopment

- New road planning

- Public transport

- Drug issues

- Sex education

- Relocation of old peoples homes

- Building a new hospital

- Opening of psychiatric home
Table 3 Degree of public involvement in decision-making by issue
Always wish to be involved

Closure of local hospital

Closure of casualty facility

Relocation of schools

Area redevelopment

New road planning
Sometimes wish to be involved

Public transport

Building a new hospital

Opening of psychiatric home

Drug issues

Food fortification

Water fluoridation

Sex education

Relocation of old peoples homes

Relocation of dental clinic
Relocation of well baby clinic

information and accessibility were expressed, together with the view that the local community is usually made aware of issues well after decisions have been finalised.

'They don't ask you what you want, they just do things their own way to suit themselves.' (Leeds, 50+, C1,C2)

Indeed subjects only saw real public involvement when it was initiated by the community in opposition to a decision strongly opposed.

'It was the community, if a group of people want to do something, they would take it upon themselves to set something up on their own.' (Oldham, 20-35, C1,C2)

Subjects were receptive to being involved in decision making but felt the initiative to inform the public and seek participation should be taken by some authority (for example the local council, the health authority).

'I think a lot should come down to the council, being proactive, you know the council, poking us and saying sit up, wake up, this is going to happen, what do you think? It is down to them to do that, shouldn't be down to us to find out what they are doing.' (Leeds, $50+, \mathrm{C} 1 \mathrm{C} 2$ )

'It is a new concept that we could perhaps affect some of these decisions, I don't know how we can.' (Leeds, 50+, C1 C2)

The groups considered a number of ways public opinion might be assessed, including referenda, citizen's juries, citizen's panels and (the most popular) question and answer sessions in the local council. Citizen's panels and juries were well received as ideas, but referenda, although inviolable and all-embracing, were not.

'The problem with referendums is always unfortunately, you get everybody putting in their two pennies and a lot of the opinion and therefore the vote is totally uninformed.' (Oldham, 50+, BC1)

Opinion surveys were seen as a good way to get a representative sample of the views of a large number of people.

On the subject of information/consultation about water fluoridation, the groups agreed that a package of measures was the best: ways in which citizens could be involved and informed combined with quantitative methods to gauge the opinion of a greater number of the public.

The decision to fluoridate

The groups agreed that they did not want to be involved in final decisions about the implementation of water fluoridation schemes and that this particular issue was best left to professionals provided that information was available to the public from an independent body:

'It depends on how major the decision is, like you said you don't want to be pestered all the time, but at the moment I don't feel involved in anything.' (Hounslow. 20-35)

'However the community gets their opinions into the frame, you have still got to have some body which will arbitrate and make the final decision otherwise you would never get a decision made and nothing will ever happen.' (Oldham, 50+)

'I agree a decision which involves a particular knowledge or a particular skill which Joe Public doesn't have, the big decisions should 
be made by the professionals. But it would be nice to be advised beforehand as to what they think they should do.' (Oldham, 50+)

'But I think we should be informed about it, to be told that it is happening.' (Leeds, 50+)

The groups also thought that water fluoridation implementation decisions should not be solely a local matter; to proceed with implementation required national government/expert endorsement .

'You have to have someone who has the intelligence - as you've found out none of us really know much about water fluoridation. Maybe if we were educated in that department then, yes, we would be able to speak up, but because we don't, we have to leave it to someone out there.' (Hounslow, 20-35)

'Surely the experts ought to get together and decide if it's a good thing or a bad thing.' (Leeds, 36-50)

'But surely this is a medical issue, it should be decided by medical people, not by politicians.' (Leeds, 36-50)

'They should have an independent medical committee that says that water should have fluoride then they should inform the government and the government tells the water companies, it's done on independent advice, I would trust that'. (Hounslow, 20-25)

'I would say with something like water fluoridation, an independent board should be set up to make that decision, independent of the water company.' (Oldham, 20-35)

\section{Discussion}

Public awareness of fluoridation has not improved over the years; as shown in this study, there is still a widespread lack of knowledge of the availability of water fluoridation. The public support the initiative, wish to be informed about water fluoridation plans but expect experts to carry the burden when it comes to final decisions, and national experts at that. It is interesting to note that, no matter what new sophisticated ways we can devise to involve the public in decision making, ${ }^{11}$ experts are still expected to take most of the responsibility for these sometimes controversial decisions.

There are policy issues raised by this and similar studies. First, the public are unwilling (and/or unable) to make decisions on complex issues such as water fluoridation, and no amount of involvement or 'consultation' will let those in positions of responsibility (public health bodies, politicians) off the hook. In other words, passing the buck by leaving the final say to the public (for example in a referendum) will be seen by the public as the government avoiding responsibility. Second, even after all the years of the so-called 'fluoridation controversy', the public in the UK and elsewhere has remained resolutely apathetic. ${ }^{12}$ Third, as water fluoridation is still urgently needed in some parts of the UK, there is nothing to be gained by waiting for the public to 'rise up' and demand fluoridation either spontaneously or after an awareness-raising campaign. There is never likely to be a national outcry for fluoridation, and it is ducking responsibility to assert otherwise.

There are a number of implications for policy makers. The general public wish to be informed about water fluoridation plans, but do not see themselves as the decision makers. The public expect experts (such as health authorities) to take the decisions and when the decision is made to implement new schemes, it should be simpler for this to happen.

1 Acheson D. Independent Inquiry into Inequalities in Health Report. 1998. HMSO, London.

2 Our Healthier Nation. London: HMSO, 1998.

3 Water Fluoridation Bill. London: HMSO, 1985.

4 Hastings G B, Hughes K, Lawther S, Lowry R. The role of the public in water fluoridation: public health champions or anti-fluoridation freedom fighters? Br Dent J 1998; 184: 39-41.

5 Hastings G B, Lawther S, Eadie D R, Haywood A, Lowry R, Evans D. General anaesthesia: who decides and why? Br Dent J 1994; 177: $332-336$.

6 Hastings G, Hughes K, Lowry R. Promoting sugar-free medicines: parents views. Br J Roy Coll Gen Practit 1997; 47: 823-824.

7 Dolan P, Cookson R, Ferguson B. Effect of discussion and deliberation on the public's views of priority setting in health care: focus group study. BMJ 1999; 318: 916-919.

8 Kitzinger J. Introducing focus groups. BMJ 1995; 311: 299-302.

9 Code of conduct. In The Market Research Society Yearbook. pp62-76. London: Market Research Society, 1996.

10 Kitzinger J. Introducing focus groups. BMJ 1995; 311: 299-302.

11 Summers A, McKeown K. Local voices: evolving a realistic strategy on public consultation. Public Health 1996; 110: 145-150.

12 Levallois P. Knowledge, perception and behaviour of the general public concerning the addition of fluoride to drinking water. Can J Public Health 1998; 89: 162-165. 